\title{
APPLICATION OF FLOWER COLOR VARIATIONS TO Impatiens balsamina L. AS AN ENVIRONMENTALLY FRIENDLY ACID-BASE INDICATOR
}

\author{
Nanik Siti Aminah*, Andika Pramudya Wardana, Alfinda Novi Kristanti, \\ Brilliana Via Safitri and Mafalda Rosa \\ Department of Chemistry, Faculty of Science and Technology, Universitas Airlangga, \\ J1. Mulyorejo, Surabaya, Indonesia 60115 \\ *E-mail : nanik-s-a@fst.unair.ac.id
}

\begin{abstract}
An acid-base titration is one of the quantitative analysis methods involving a high-polluting, harmful, hazardous, and relatively expensive synthetic indicator. The development of the concept of green chemistry encourages research to invent natural indicators that are more environmentally friendly. Impatiens balsamina L. flower has a variety of colors and contains anthocyanin pigments. Rose pink, red, violet, orangish red, and pink Impatiens balsamina L. flower were extracted with acidified ethanol solvent. All five I. balsamina L. flower extracts indicate discoloration on $\mathrm{pH}$ range 10-12. Violet flower extract has an error percentage of strong acid-strong base titration which was $50.48 \pm 2.18 \%$, while in strong acid-weak base titration was $19.27 \pm 1.15 \%$. Meanwhile, it cannot be applied in weak acids-strong base titration. Thus, I. balsamina L. flowers can be used as an alternative to environment-friendly natural acid-base indicators.

Keywords: Acid-base, Green Chemistry, Impatiens balsamina L., Natural Indicator, Titration
\end{abstract}

(C) RASĀYAN. All rights reserved

\section{INTRODUCTION}

The beginning of green chemistry was dominated by the green organic synthesis in various branches of the chemical industry. ${ }^{1}$ This green chemistry activity has been applied to the role of analytical chemists in making laboratory practices more environmentally friendly. ${ }^{2}$ Green analytical chemistry (GAC) emerged in 2000, where the main principle was to replace toxic reagents, reduce the number of reagents used and the waste produced dramatically, thereby reducing or avoiding the side effects of the analytical process. It is carried out to increase the awareness of environmental problems caused by analytical processes and industries in the chemical field. ${ }^{3}$

Titration is the most common laboratory method carried out by quantitative chemical analysis used to determine the concentration of analytes. ${ }^{4}$ Some scientists frequently conducted titration using highpolluting, harmful, hazardous, and relatively expensive synthetic indicators ${ }^{4}$. Both dye and synthetic indicators have become a cause of concern because of the damages to the environment and living systems. Therefore, efforts to replace hazardous synthetic indicators with the natural one obtained from plant sources have been made. ${ }^{5}$ Therefore, various studies on the indicators from natural products are being carried out widely by many scientists around the world because they are less dangerous, low cost, easily available, and environmentally friendly. ${ }^{6}$ Research on acid-base indicators of natural products includes flower estates such as Nerium oleander and Catharanthus roseus ${ }^{7}$, Antirrhium majus and Dianthus plumarius ${ }^{8}$, Quisqualis indica, Pentas lanceolate, Malabathricum melastoma, Impatiens acaulis ${ }^{9}$, Thunbergia erecta ${ }^{10}$, and Syzygium cumini. ${ }^{11}$

Anthocyanin compounds are water-soluble pigments and are naturally found in various types of plants. The color of red to blue flowers comes from anthocyanins, a class of flavonoids. Flower color is one of the most important characteristics of floricultural crop. ${ }^{12}$ Color is given by anthocyanin due to its long and conjugated double bond arrangement, so it can absorb light in the visible light range.

Rasayan J. Chem., 12(4), 2116-2123(2019)

http://dx.doi.org/10.31788/RJC.2019.1245498

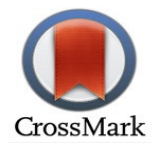


I. balsamina is a flowering plant that is widely grown and belongs to the family of Balsaminaceae originating from India. Balsam is commonly known as garden balsam, rose balsam and Gulmehdiin Hindi. ${ }^{13}$ This plant is a qualitative short-day plant, free-flowering, semi-hard and compact, can withstand heavy rain and live in high humidity. Balsamina is a popular species in northern India. ${ }^{14}$ This plant can also be grown in Indonesia and has been reported to grow in Pontianak, West Kalimantan. ${ }^{15}$ I. balsamina L. plants are assumed to have anthocyanin since it has a variety of flower color, from red to purple. Thus, it is necessary to conduct research on the color variations of I. balsamina L. flowers as a substitute for synthetic indicators that are more environmentally friendly, low cost, less dangerous and easily available.

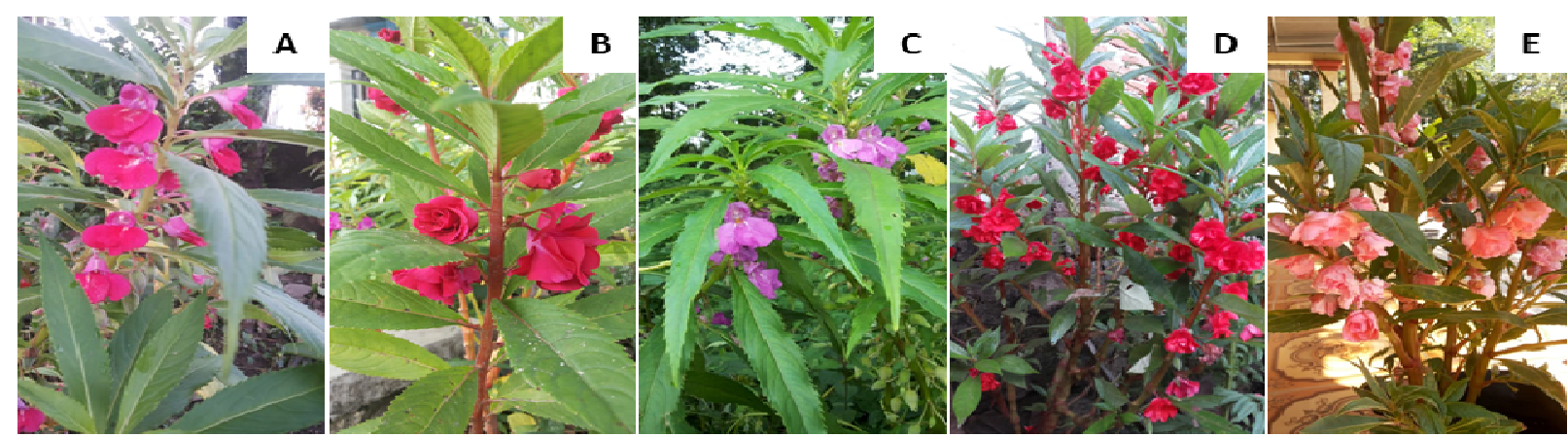

Fig.-1: Impatiens balsamina L. flower (A) Rose Pink, (B) Red, (C) Violet, (D) Orangish Red, dan (E) Pink

\section{Material}

\section{EXPERIMENTAL}

The materials used in this research were five Impatiens balsamina L. flowers with various colors, namely rose pink, red, violet, orangish red, and pink. The chemicals used were $\mathrm{HCl}, \mathrm{NaOH}, \mathrm{CH}_{3} \mathrm{COOH}, \mathrm{NH}_{4} \mathrm{OH}$, ethanol 96\%, phenolphthalein (pp), methyl red, and distilled water.

\section{Apparatus}

The tools used in this research were a UV-Vis spectrometer, Beaker glass, Erlenmeyer flask, pipette, $\mathrm{pH}$ meter, rotary vacuum evaporator, Buchner funnel, burette, mortar and pestle.

\section{Extraction of I. Balsamina L Flower.}

Samples in the form of fresh flowers from the five I. balsamina L. flowers macerated with $96 \%$ ethanol acidified with $1 \% \mathrm{HCl}$ for 30 minutes. The maceration results of each flower were then filtered and the extract obtained was then concentrated with a rotary vacuum evaporator at $35^{\circ} \mathrm{C}$ until thick extracts were obtained $^{10}$.

\section{Determination of pH Range of Indicator Obtained From I. Balsamina L. Flower Extract}

The 3 drops of each indicator of I. balsamina L. flower extract was dropped onto $5 \mathrm{~mL}$ solution of $\mathrm{pH} 1$ to 14. The color change was observed and the absorption bands were determined by UV-Vis spectrophotometer at wavelengths of 200-600 nm. The $\mathrm{pH}$ range was determined from color changes and absorption bands from the solutions which have been given an indicator of Impatiens balsamina L. flower extract.

\section{Determination of Error Percentage of Indicator Obtained From I. Balsamina L. Flower Extract}

Error percentage of the five indicators obtained from I. balsamina L. flower extract with variations in flower colors was determined by the acid-base titration method and compared to standard indicators. Titrations used were strong acid-strong base, strong acid-weak base, weak acid-strong base, and weak acid-weak base titration with standard phenolphthalein and methyl red indicators.

$$
\% \text { Error }=\mid \frac{\text { Experimental value }- \text { Theoritical value }}{\text { Theoritical value }}-x 100
$$


RASĀYAN J. Chem.

Vol. 12 | No. 4 |2116 - 2123| October - December | 2019

\section{RESULTS AND DISCUSSION}

Absorption Bands of I. balsamina L. Flower Extract

The absorption bands of the I. balsamina L. flower extracts were shown in Fig.-2. Based on the UV-Vis spectra above, it indicated that the absorption bands of extract A were at 505.5, 324.5 and $248.5 \mathrm{~nm}$, extract B were at $517.5 \mathrm{~nm}, 320 \mathrm{~nm}$ and $266.5 \mathrm{~nm}$, extract $C$ were at $533.5 \mathrm{~nm}, 345 \mathrm{~nm}$ and $263.5 \mathrm{~nm}$, extract D were at $503 \mathrm{~nm}, 317 \mathrm{~nm}$ and $249 \mathrm{~nm}$, while extract $E$ was at $519.5 \mathrm{~nm}, 339.5 \mathrm{~nm}$ and $249 \mathrm{~nm}$. It shows that the five colors of I. balsamina L. flower are assumed to contain anthocyanin compounds. The anthocyanin compound has the characteristics of two absorption regions at wavelengths that are UV (260$280 \mathrm{~nm})$ and visible $(490-550 \mathrm{~nm}) .{ }^{16}$ The color of anthocyanin is caused by a long conjugated double bond arrangement; thus, it can absorb light in the visible light range. The color caused by anthocyanin depends on the acidity $(\mathrm{pH})$ of the environment. Therefore, this pigment can be used as a $\mathrm{pH}$ indicator. However, it is not possible to distinguish the various types of anthocyanins based solely on the UV-Vis spectrum.

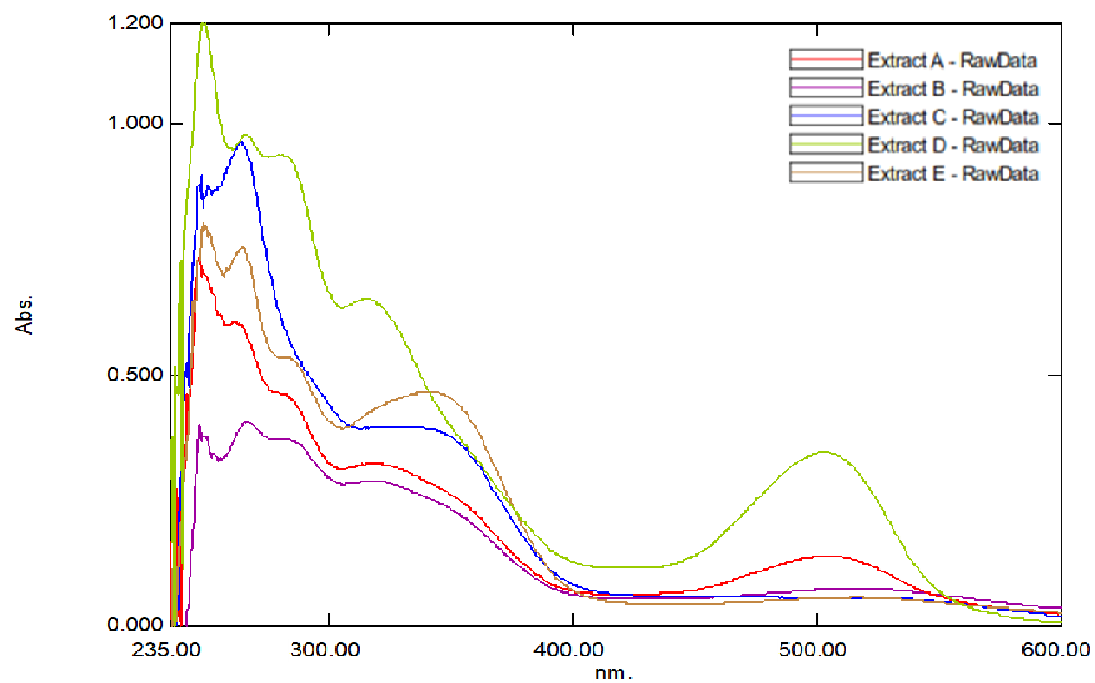

Fig.-2: UV-Vis Spectra of I. balsamina L. Flower Extract By Various Flower Colours, (A) Rose pink, (B) Red, (C) Violet, (D) Orangish pink, and (E) Pink

\section{Determination of pH Range On Indicator Obtained From I. Balsamina L. Flower Extract}

The $\mathrm{pH}$ range of the five indicators obtained from Impatiens balsamina $\mathrm{L}$. flower extract was determined based on its color changes and absorption bands in acid-base solutions ( $\mathrm{pH} 1-14)$. The change in the indicator color of the 5 flowers in the $\mathrm{pH}$ solution was shown in Fig.-3.

There are four forms of anthocyanin structure in equilibrium which cause color changes in anthocyanincontaining flower extracts. All five indicators can be inferred that it changes from red to orange color at acidic $\mathrm{pH}(1-2)$, it is because anthocyanin forms a flavylium cation. The increase in $\mathrm{pH}$ change causes the color of the extract to fade almost to colorless due to the formation of a pseudo base carbinol from anthocyanin caused by the flavylium cation hydration which subsequently undergoes tautomeric formation of chalcone pseudo base. At alkaline $\mathrm{pH}$, anthocyanin forms a bluish-colored quinonoidal base.

Color changes at $\mathrm{pH}$ 1-14 from the five Impatiens balsamina L. flower extracts were supported by changes in the UV-Vis absorption band. It is one of the supporting data in determining the $\mathrm{pH}$ range of each flower extract. The UV-Vis spectra of the five I. balsamina L. flower extracts with respect to $\mathrm{pH}$ changes were shown in Fig.-5.

The absorption band shift of extract A (Fig.-5. A1 and A2), extract B (Fig.-5. B1 and B2), and extract E (Fig.-5. E1 and E2) at pH 1-10 were not significant, while at $\mathrm{pH}$ 11-12 absorption bands I and II were significantly shifted. The absorption band of Extract $\mathrm{C}$ (Fig.-5. C1 and C2) was relatively constant at pH 1-9, while at $\mathrm{pH}$ 10-11 the bands I and II shift were significant. On extract D (Fig.-5. D1 and D2), the absorption bands I and II at pH 1-10 were relatively stable, but at pH 11-12, a significant absorption band shift occurred. Extract D also undergoes a shift in absorption bands at $\mathrm{pH} 12-13$ 
RASĀYAN J. Chem.

Vol. 12 | No. 4 |2116 - 2123| October - December | 2019

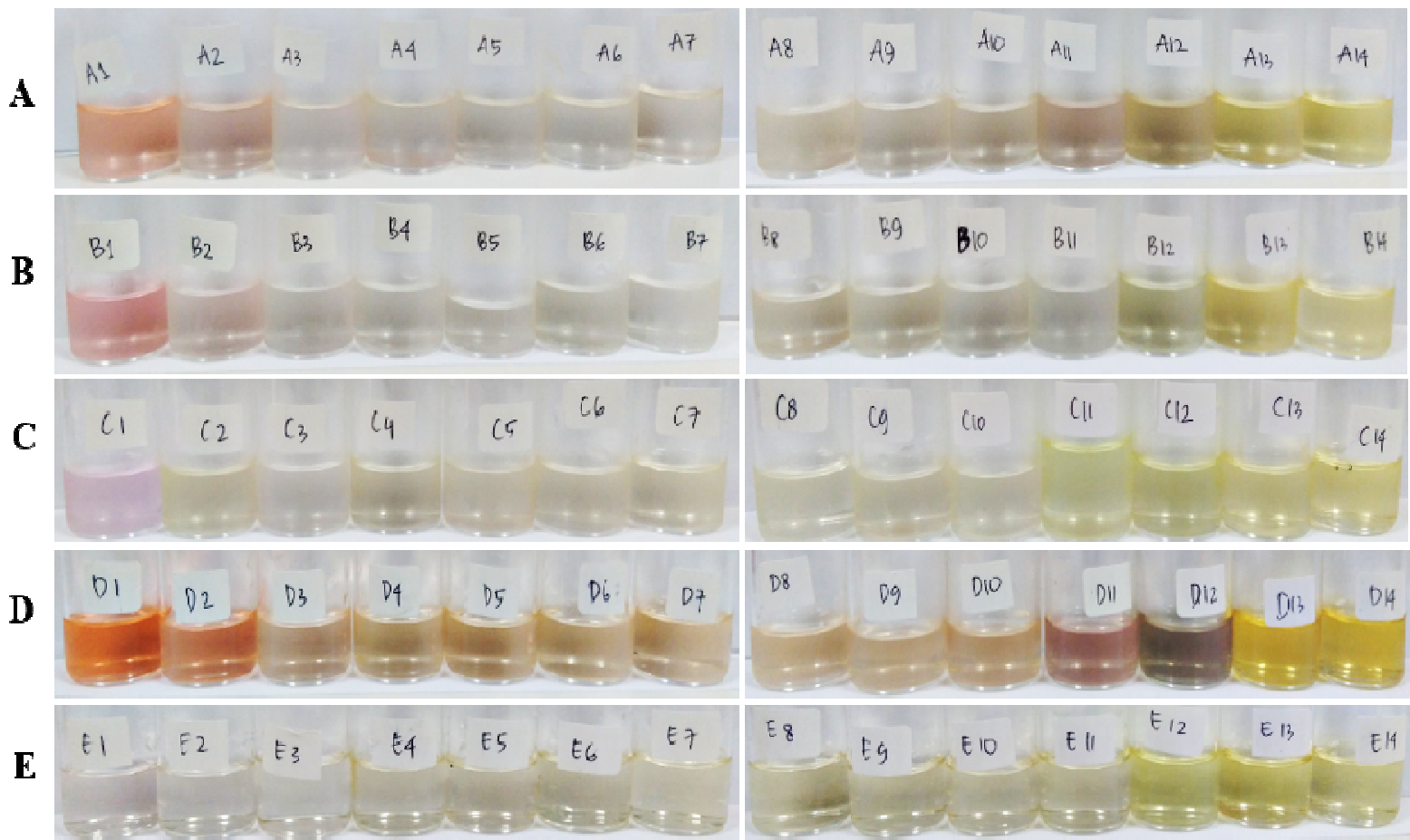

Fig.-3: The Color Changes Of Indicator Obtained From Impatiens balsamina L. Flower Extract, (A) Rose Pink, (B) Red, (C) Violet, (D) Orangish Red, dan (E) Pink

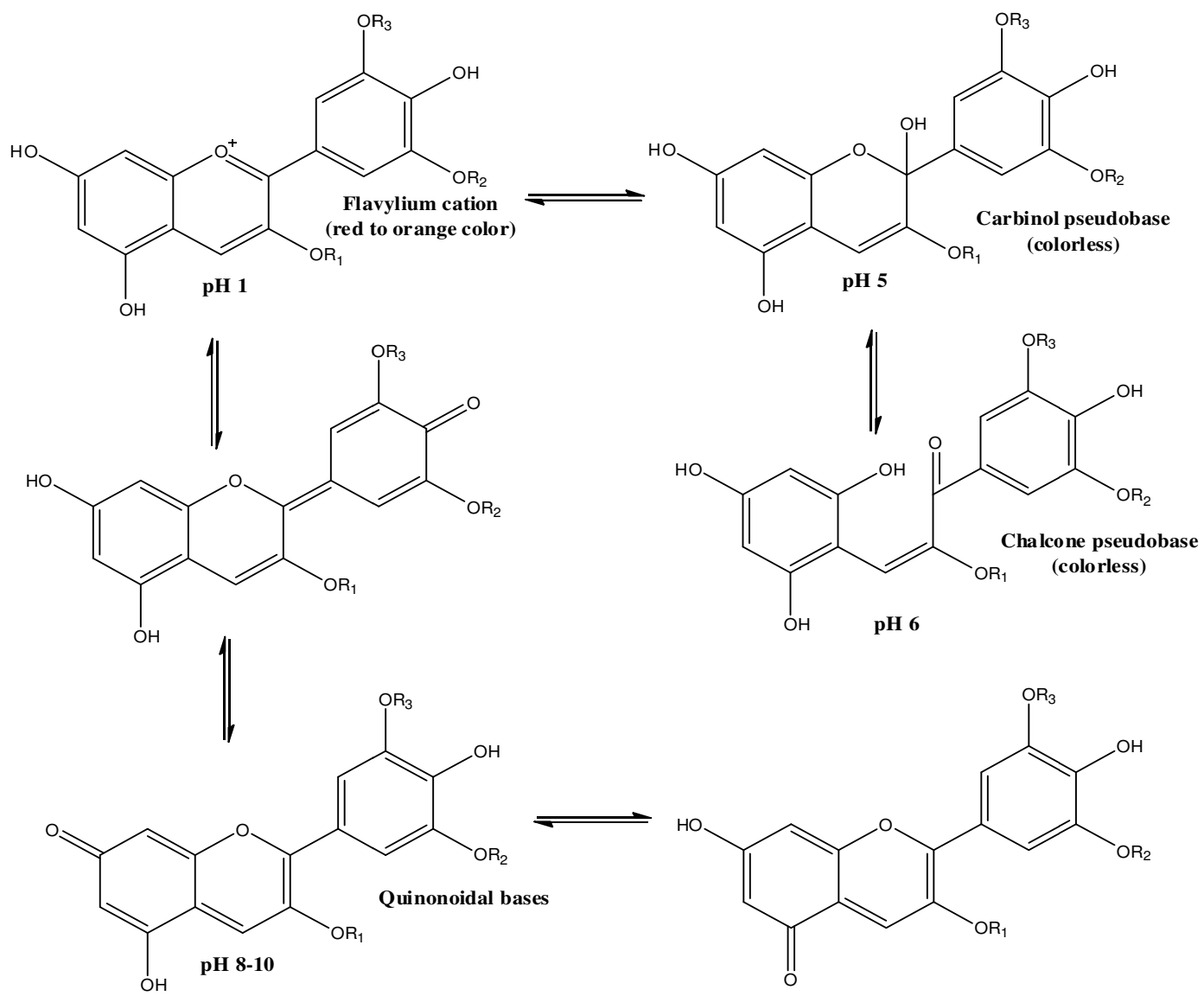

Fig.-4: Effect of pH on The Form of Anthocyanin Compounds (Modified) ${ }^{17}$ 
RASĀYAN J. Chem.

Vol. 12 | No. 4 |2116 - 2123| October - December | 2019

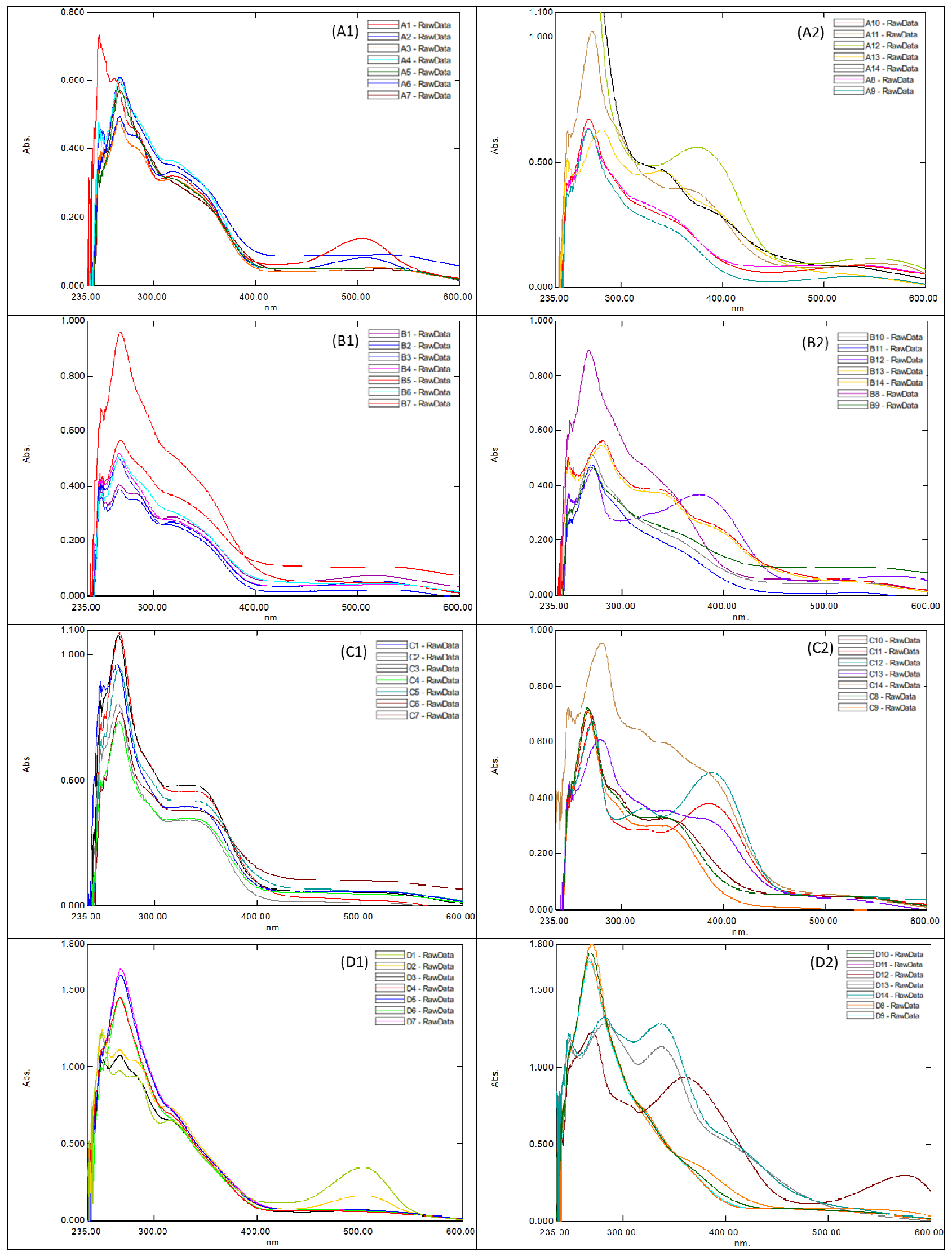


RASĀYAN J. Chem.

Vol. 12 | No. 4 |2116 - 2123| October - December | 2019

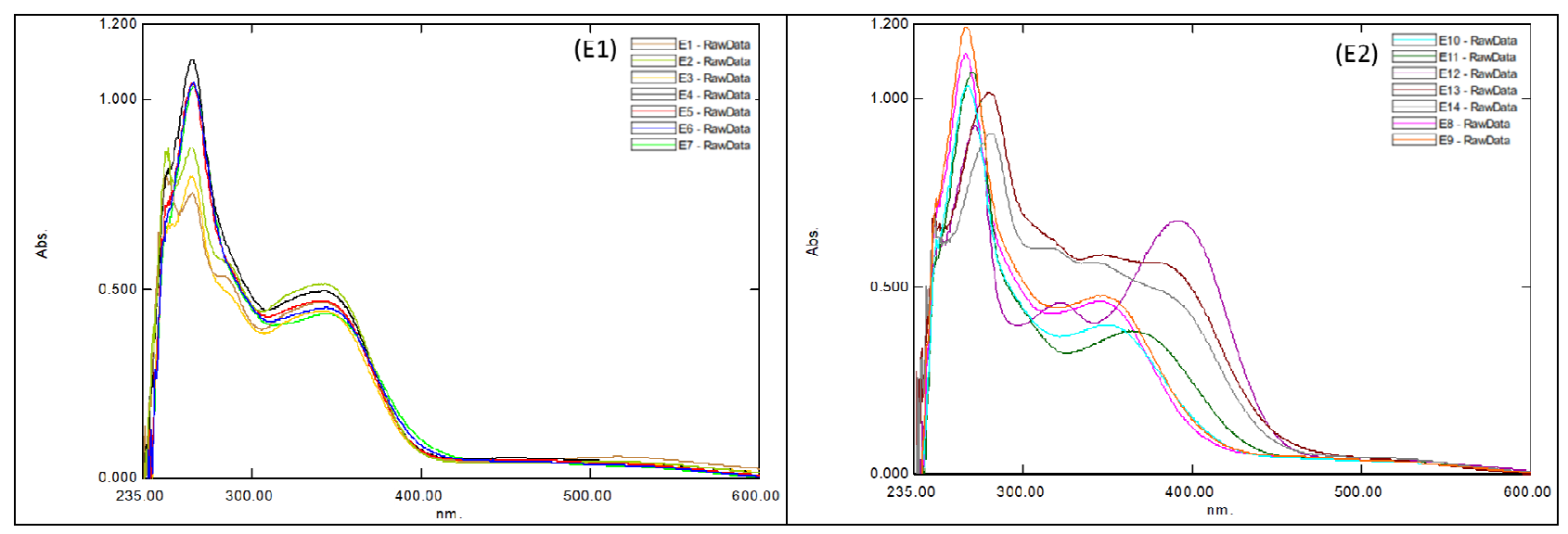

Fig.-5. UV-Vis Spectra Of Impatiens Balsamina L. Flower Extract On pH Value 1-14. (A1) Flower Extract A On pH Value 1-7, (A2) Flower Extract A On pH Value 8-14, (B1) Flower Extract B On pH Value 1-7, (B2) Flower Extract B On pH Value 8-14, (C1) Flower Extract C On pH Value 1-7, (C2) Flower Extract C On pH Value 8-14, (D1) Flower Extract D On pH Value 1-7, (D2) Flower Extract D On pH Value 8-14, (E1) Flower Extract E On pH Value 1-7, (E2) Flower Extract E On pH Value 8-14.

Based on the color changes and absorption band shifts of I. balsamina $\mathrm{L}$. flower extract, the $\mathrm{pH}$ range of the flower extract indicator can be determined as shown in Table-1.

Table-1: Color Change and Absorption Band of the I. Balsamina L. Flower Extracts Indicators

\begin{tabular}{|c|c|c|c|c|c|}
\hline \multirow{2}{*}{ No. } & \multirow{2}{*}{$\begin{array}{l}\text { Flower } \\
\text { extract }\end{array}$} & \multirow{2}{*}{ Color change } & \multicolumn{3}{|c|}{ Bands $\left(\lambda_{\max } \mathrm{nm}\right)$} \\
\hline & & & $\mathrm{I}$ & II & III \\
\hline \multirow[t]{3}{*}{1} & \multicolumn{5}{|c|}{$\mathrm{A}$} \\
\hline & $\mathrm{pH} 11$ & Orange & 369.5 & 271 & - \\
\hline & $\mathrm{pH} 12$ & Reddish yellow & 375 & 245 & - \\
\hline \multirow[t]{3}{*}{2} & \multicolumn{5}{|c|}{$\mathrm{B}$} \\
\hline & $\mathrm{pH} 11$ & Colorless & - & 352.5 & 271 \\
\hline & $\mathrm{pH} 12$ & Bluish yellow & 562.5 & 376 & 271 \\
\hline \multirow[t]{3}{*}{3} & \multicolumn{5}{|c|}{$\bar{C}$} \\
\hline & $\mathrm{pH} 10$ & Colorless & 352 & 268.5 & - \\
\hline & pH 11 & Yellow & 386 & 271 & - \\
\hline \multirow[t]{4}{*}{4} & \multicolumn{5}{|c|}{$\mathrm{D}$} \\
\hline & pH 11 & Purplish red & - & 367.5 & 269.5 \\
\hline & $\mathrm{pH} 12$ & Violet & 574.5 & 360.5 & 270 \\
\hline & pH 13 & Yellow & 338 & 283 & 248 \\
\hline \multirow[t]{3}{*}{5} & \multicolumn{5}{|c|}{$\mathrm{E}$} \\
\hline & $\mathrm{pH} 11$ & Colorless & 339.5 & 249.5 & \\
\hline & pH 12 & Yellow & 391.5 & 271.5 & \\
\hline
\end{tabular}

Error Percentage of Indicator Obtained From I. Balsamina L Flower Extract

Acid-base titration is used to determine the error percentage of the five Impatiens balsamina L. flower extracts. The error percentage of each flower was shown in Table-2.

Table-2: Error Percentage of the Five Impatiens Balsamina L. Flower Extract Indicators

\begin{tabular}{c|c|c|c|c|c|c}
\hline \multirow{2}{*}{ No. } & \multirow{2}{*}{ Type of titration } & \multirow{2}{*}{ Indicator } & \multicolumn{3}{|c|}{ End point $\mathrm{pH}$} & \multirow{2}{*}{$\%$ Error \pm SD } \\
\cline { 3 - 7 } & & & $\mathrm{I}$ & $\mathrm{II}$ & $\mathrm{III}$ & \\
\hline \multirow{2}{*}{1} & Strong acid-Strong base & Phenolphthalein & 8.7 & 8.5 & 8.9 & $24.29 \pm 2.86$ \\
\cline { 3 - 7 } & & $\mathrm{A}$ & 11.3 & 11.5 & 11.2 & $61.90 \pm 2.18$ \\
\cline { 3 - 7 } & & $\mathrm{B}$ & 11.4 & 11.2 & 11.5 & $62.38 \pm 2.18$ \\
\hline
\end{tabular}


RASĀYAN J. Chem.

Vol. 12 | No. 4 |2116 - 2123| October - December | 2019

\begin{tabular}{|c|c|c|c|c|c|c|}
\hline \multirow{5}{*}{ No. } & \multirow{5}{*}{ Type of titration } & \multirow{2}{*}{ Indicator } & \multicolumn{3}{|c|}{ End point $\mathrm{pH}$} & \multirow{2}{*}{$\%$ Error $\pm \mathrm{SD}$} \\
\hline & & & I & II & III & \\
\hline & & $\mathrm{C}$ & 10.7 & 10.5 & 10.4 & $50.48 \pm 2.18$ \\
\hline & & $\mathrm{D}$ & 11.1 & 11.1 & 11.2 & $59.05 \pm 0.82$ \\
\hline & & $E$ & 11.9 & 12 & 12.3 & $72.38 \pm 2.97$ \\
\hline \multirow[t]{6}{*}{2} & \multirow[t]{6}{*}{ Strong acid-Weak base } & Phenolphthalein & 8.8 & 8.9 & 8.8 & $1.30 \pm 0.66$ \\
\hline & & $\mathrm{A}$ & 11.5 & 11.4 & 11.4 & $31.12 \pm 0.66$ \\
\hline & & $\mathrm{B}$ & 11.1 & 11.3 & 11.2 & $28.44 \pm 1.15$ \\
\hline & & $\mathrm{C}$ & 10.4 & 10.3 & 10.5 & $19.27 \pm 1.15$ \\
\hline & & $\mathrm{D}$ & 11.2 & 11.1 & 11.2 & $28.06 \pm 0.66$ \\
\hline & & $\mathrm{E}$ & 12.3 & 12.4 & 12.2 & $41.06 \pm 1.15$ \\
\hline \multirow[t]{6}{*}{3} & \multirow[t]{6}{*}{ Weak acid-Strong base } & Methyl Red & 5.4 & 5.3 & 5.6 & $2.90 \pm 2.89$ \\
\hline & & A & 11.2 & 11.3 & 11.3 & 100 \\
\hline & & B & 11.3 & 11.4 & 11.2 & 100 \\
\hline & & $\mathrm{C}$ & 10.2 & 10.1 & 10.1 & 100 \\
\hline & & $\mathrm{D}$ & 11.1 & 11.2 & 11.2 & 100 \\
\hline & & $\mathrm{E}$ & 11.8 & 11.9 & 12 & 100 \\
\hline
\end{tabular}

The error percentage of the five indicators in several titrations shows that at strong base-strong acid titration are all above 50\%, indicating that the $\mathrm{pH}$ range of the flower extract indicator is not suitable for strong base-strong acid titration because the equivalence point at this titration is at $\mathrm{pH} 7$ while the $\mathrm{pH}$ range of the indicators around $\mathrm{pH} 10-12$. Meanwhile, on the strong acid-weak base titration, the error percentage given by each flower extract indicator is relatively smaller. Extract $\mathrm{C}$ has the best error percentage, which is $19.27 \% \pm 1.15$. The titration of the weak acid-strong base from all extract indicators has an error rate of $100 \%$, showing that the indicator cannot be employed in weak acid-weak base titration. The titration of the weak acid-strong base has an equivalent point at around $\mathrm{pH} 5.28$ while the five I. balsamina L. flower extract indicators have $\mathrm{pH}$ range of 10-12 (bases) which poses this indicator not to be used in weak acid-strong base titration applications.

\section{CONCLUSION}

I. balsamina $\mathrm{L}$. flowers with various color variations can be used as an alternative acid-base indicator that is environmentally friendly. The $\mathrm{pH}$ range of the indicator was at $\mathrm{pH} 10-12$. The best error percentage of I. balsamina L. flower extract was violet-colored flowers, on strong acid-weak base titration with the error percentage $50.48 \pm 2.18 \%$. In the strong acid-weak base, the error percentage was $19.27 \pm 1.15 \%$. Meanwhile, weak acids-strong base titration cannot be employed.

\section{REFERENCES}

1. A. Gałuszka, Z. Migaszewski, J. Namieśnik, Trends Anal. Chem., 50, (2013), DOI: 10.1016/j.trac.2013.04.010

2. M. Tobiszewski, A. Mechlińska, J. Namieśnik, Chem. Soc. Rev., 39(8), 2869(2010), DOI: 10.1039/b926439f

3. S. Armenta, S. Garrigues, M. de la Guardia, Trends Anal. Chem., 27(6), 497(2008), DOI: 10.1016/j.trac.2008.05.003

4. N. Kapilraj, S. Keerthanan, M. Sithambaresan, J. Chem., (2019), DOI: 10.1155/2019/2031342

5. A. Nair, A. Kelkar, S. Kshirsagar, A. Harekar, K. Satardekar, S. Barve, S. Kakodkar, Journal of Innovations in Pharmaceutical and Biological Sciences, 5(4), 1(2018).

6. P.M.A. Khan, M. Farooqui, J. Adv. Scient. Res. 2(4), 20 (2011)

7. S. Kadam, A. Yadav, V. Raje, K. Waghmare, Der Pharma Chemica, 5(1), 296 (2013).

8. S. Jaspreet, A. Kanika, N. Parminder, D. Geetam, I.R.J.P. 2, 4 (2011)

9. E. Vadivel, S. D. Chipkar, Int. J. Pharm. Pharm. Sci., 8(6), 250(2016)

10. Tukiran, A. P. Wardana, Rasayan J. Chem., 11(2), 773(2018), DOI: 10.31788/RJC.2018.1121844

11. M. Zulfajri, Muttakin. Rasayan J. Chem. 11(1), 135(2018), DOI: 10.31788/RJC.2018.1111983 
12. N. Okitsu, T. Mizuno, K. Matsui, S.H. Choi, Y. Tanaka, Plant Biotechnology, 35(1), 9(2018), DOI: 10.5511/plantbiotechnology.18.0104a

13. A.K. Singh, 2014, Breeding and Biotechnology of Flowers: Vol. 2 Garden flowers, New India Publishing Agency, New Delhi, p.698.

14. T.K. Lim, 2014, Impatiens balsamina. In: Edible Medicinal and Non-Medicinal Plants, Springer, Dordrecht, pp 537-547.

15. H. IH, I. Fajriaty, T. Wijaya, M. Hafizh, Nus. Biosci., 10(1), 58(2018), DOI: 10.13057/nusbiosci/n100109

16. J. B. Harborne, Biochem J., 70(1), 22(1958), DOI: 10.1042/bj0700022

17. A. Castañeda-Ovando, Ma. de L. Pachero-Hernández, Ma. E. Páez-Hernández, J. A. Rodríguez, C. A. Galán-Vida, Food Chemistry, 113(4), 859(2009), DOI: 10.1016/j.foodchem.2008.09.001

[RJC-5498/2019] 